\title{
The coordination of visual and tactual input in infants
}

\author{
T. G. R. BOWER, ${ }^{1}$ J. M. BROUGHTON, AND M. K. MOORE
}

HARVARD UNIVERSITY

Traditionally it has been taught that "touch teaches vision" in ontogeny. Recent experiments have shown that in judgment situations vision dominates touch, a finding that has been taken to weaken the traditional argument. The force of the finding is vitiated to some extent by the functional dominance of touch. Developmental experiments show that initially in ontogeny vision is functionally dominant, strengthening the case against the traditional argument.

The relation between vision and touch has puzzled psychologists for three centuries. In adults, visual variables specify many object properties that seem to belong more appropriately to the tactual domain. Thus, adults can by eye determine the palpability or impalpability of units in their visual field (Michotte, 1962; Katz, 1935). Adults can also register by eye the three-dimensional form of objects, even though at least one face of an object must be invisible to them. A convenient hypothesis to account for this ability posits that initially, in ontogeny, object properties such as palpability and solid form can be picked up only via the sense of touch, and thus the developing ability of the visual system to register these properties comes about as the result of associations between visual variables and the object properties detected by the sense of touch.

The hypothesis outlined above, or some version of it, has been around since the days of Bishop Berkeley (1709). Piaget has recently adopted essentially the same position (Piaget \& Inhelder, 1966). Despite its long history, the hypothesis has not been subjected to a great deal of experimental test or critical analysis. Research has tended to focus on the somewhat different problem of whether vision or touch will dominate when the two are placed in conflict. The result that vision dominates (e.g., Rock, 1966) in such conflict situations does seem to weaken the argument that touch is a primary and vision but a secondary source of information about object properties.

The "touch teaches vision" theory reflects a somewhat unsophisticated view of the perceptual process. When we grasp an object, we produce a set of deformations in our skin surface whose exact pattern is a function of the size, shape, and hardness of the object and the patterning of hand and finger movements used to explore it. Such a deformation pattern gives us no more direct access to object properties than does the pattern of light energies on the retina that an object also produces. The input pattern in both eyes is specific to the object but in neither case is the relationship other than abstract or mediate. At a sensory level, the tactile and visual input are quite unlike one another. At a perceptual level, the two inputs are quite equivalent, both specifying such object properties as size, shape, and hardness. Both sensory inputs, so different from one another and from the terminal percept, must be transduced within the organism to a common perceptual structure. The fact is that both inputs must be transduced or structured. There is no a priori reason to assume that either one is prestructured in ontogeny and the other not. Only if one ignores the perceptual problems posed by the sense of touch can one assign touch any prior status.

As we mentioned above, the standard way of assessing the relation between vision and touch has been to place the two in conflict and ask the $S$ if he is aware of a conflict and, if not, whether the visual or tactile input dominates. Thus Rock had Ss view an object through an optical device, which magnified one dimension or minified a11 dimensions, while simultaneously grasping the object. Judgments of shape or size, whether assessed by drawings, successive visual matches, or successive tactual matches indicated that vision completely dominated the judgment. However, while vision completely dominated judgments, it cannot be said that it was functionally dominant. The Ss were able to grasp a minified square without crushing it. Their finger positioning obviously did not reflect pure visual control, otherwise they would have crushed the square or their fingers. Similarly, the Ss were able to hold the objects presented in the shape-distortion experiments, something they could not have done had their finger positioning reflected the visual percept. At this more functional level, touch was completely dominant. It thus seems fair to conclude that vision-touch conflict does produce a conflict in the $S$, one modality controlling judgment, the other, performance. The conclusion might well be vitiated by more careful analysis of performance. That such a conclusion is possible focuses attention on the role of vision and touch in controlling prehensile behavior, their normal functional role.

There would be little point in studying such functions in adults, however, if the primary aim is to understand an ontogenetic process. It is more profitable to study development as it occurs, rather than to try to infer it from relearning processes in adults. Therefore, we decided to study the intercoordination of vision and touch in infants.

The basic facts that we wished to establish were whether vision precedes touch or vice versa as a source of information about such properties as object size, object shape, and object hardness. The "touch teaches vision" hypothesis clearly asserts the necessary priority of touch over vision and also asserts that only by association with touch can vision come to specify these properties. The "touch teaches vision" hypothesis must also assert that early in ontogeny there can be no conflict between vision and touch since the former would not be sufficiently articulated to conflict with the latter. Awareness of conflict should thus develop pari passu with the putative articulation of the visual system and might disappear again if vision did establish predominance. We therefore required some method of ascertaining the relative efficiency of vision and touch as specifiers of size, shape, and hardness plus some method of putting vision and touch into conflict that allowed us to assess the infant's response to the conflict.

\section{EXPERIMENT 1}

\section{Method}

The method adopted was primarily observational. The efficiency of grasping was observed under two conditions. In one, an object was placed in the infant's hand out of his sight. In the other, the object was presented to the infant visually. He was allowed to reach for it and grasp it. Analysis of anticipatory hand positioning allowed us to assess visual control, while after grasping had taken place the efficiency of grasping could be assessed (as it occurred) under simultaneous tactile and visual control. A pure visual presentation was obtained by using a virtual object (Fig. 1), obtained by use of a stereoscopic 


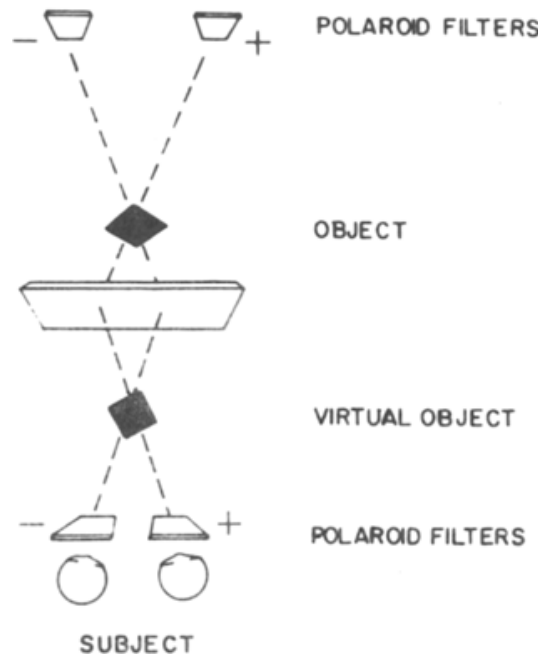

Fig. 1. Diagram of the shadow-caster.

shadow-caster. This device allowed us to study prehensile behavior as it occurs under pure visual control. It also allowed us to study the infants' response to a conflict between vision and touch. The stereoscopic shadow-caster allows one to present objects that are visually hard, solid, and three-dimensional, but that are yet totally impalpable. There is thus a complete mismatch between visual and tactile input and a genuine conflict between vision and touch at a very basic level, the specification of palpability.

A wide variety of differently shaped and sized objects were presented, ranging from a $3 \times 1 / 8$ in. tube to a 4-in.-diam sphere. Objects were made of metal, hard plastic, soft plastic, and foam rubber. The objects presented in the stereoscope were of colored transparent plastic.

The lamps used in the virtual object presentation were Sylvania $\mathrm{C} 100$ point sources. The screen was Polacoat Stereoscreen. Viewing distance was $40 \mathrm{~cm}$. The infants wore individually fitted Polaroid goggles.

Eighty infants aged between 6 days and 6 months served as Ss. Naive groups were introduced to the experiment at 7 days $(\mathrm{N}=40) .2$ months $(\mathrm{N}=8), 3$ months $(\mathrm{N}=8), 4$ months $(\mathrm{N}=8), 5$ months $(\mathrm{N}=8)$, and 6 months $(\mathrm{N}=8)$, and were seen longitudinally thereafter. The infants sat or lay in the most comfortable position for them. Tactual and tactual-visual presentations were made by an $E$. In the tactual condition, the object was placed in the infant's hand out of his sight. In the tactual-visual condition, the object was presented in sight and the infant allowed to reach out and grasp it. The same toys were presented in tactual and tactual-visual conditions. Order of presentation was randomized. The transparent toys were used only in the virtual object condition. Half of the infants received virtual object presentation first, the other half last. Behavior was filmed for subsequent analysis.

\section{Results}

Anticipatory hand shaping under visual control occurred at all ages (Fig. 2). Hand shaping when the object was placed in the hand was poor. A stereotyped closure movement-which was not adapted to the object-occurred. Seventy-two instances of anticipatory hand shaping were discernible in the 7-day-old group. No instances of appropriate, tactually controlled behavior were seen.

At every age, a seen object was reached for by every infant. Not until 3 months did the presence of an object in the hand elicit looking.

Response to conflict. At every age up to 5 months, the virtual object produced frustration and tears. The number of attempts to grasp the object before frustration set in increased with age. The pattern of grasping changed markedly with age. Infants up to and including 4 months of age grasped at the object repeatedly in a stereotyped fashion, invariably closing their fingers on the object. The 5-month group and the 6-month group, by contrast, did not close their hands on the object but stopped the grasp with hands open. After this, a variety of exploratory behaviors occurred which included rubbing the hands together, patting at the object with open hand, pinching at its locus, poking at it, and others, all of which looked like exploratory tactile behaviors.

\section{Discussion}

These results indicated an early dominance of vision over touch. However, it seemed possible that the poor tactile control might reflect poor motor programming and not a deficit in the tactual perceptual system. An attempt was made to control this by presenting virtual objects that were not visually hard or palpable. It seemed that if this visual presentation elicited a different program of prehensile behavior from the normal one, then the deficit could not lie in the motor programming but must reside in the tactual perceptual system or between that system and motor control.

\section{Method \\ EXPERIMENT 2 \\ Our intention was to produce objects}

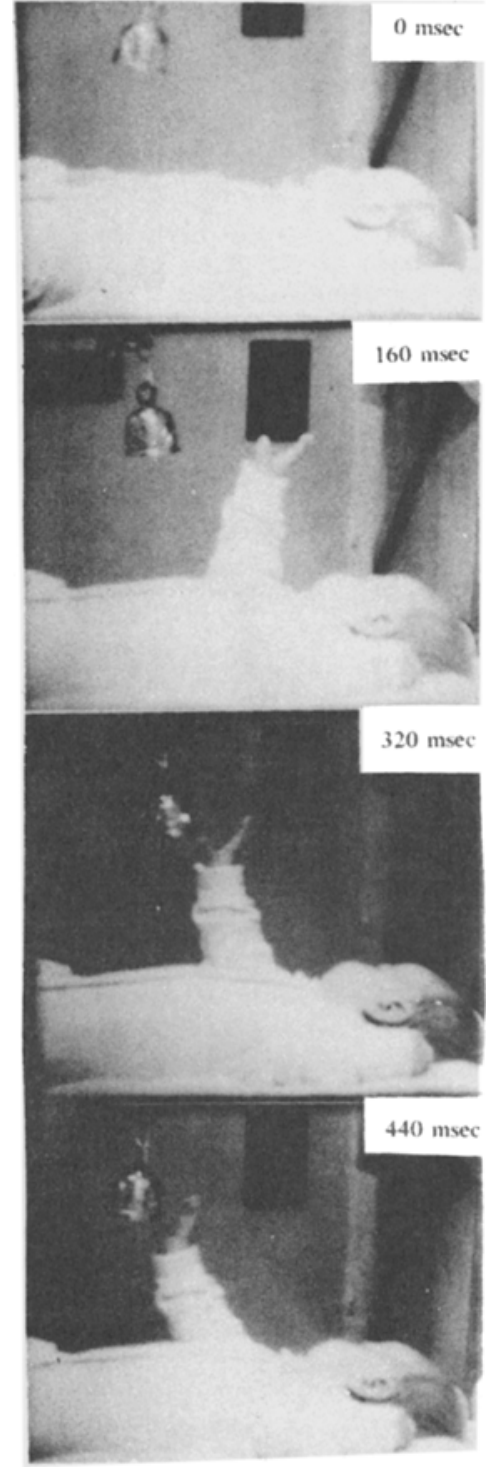

Fig. 2. An example of anticipatory hand-shaping.

that were not visually hard or palpable. The first object used was produced by projecting the image of an aperture in depth. The resulting object stood out in depth but did not have visible microstructure and lacked either a forward or a rear boundary. It looked like a patch of film color in depth. A second version was produced by covering the aperture with an oil film so that the patch in depth had a continuously flowing appearance.

Five naive infants aged $3 \frac{1}{2}$ months served as Ss.

\section{Results}

The infants displayed the exploratory hand and finger pattern typical of the 5- to 


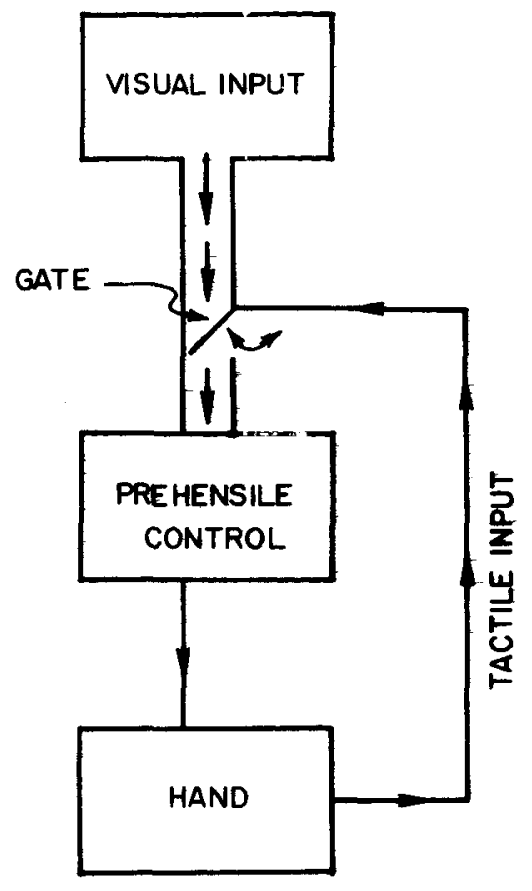

Fig. 3. A flow diagram representing a possible model of the interaction between visual and tactile input in the control of prehensile behavior.

6-month-old group. This was true of all of them. The behaviors that did not appear in the normal situation until 5-6 months could thus be elicited at $3 \frac{1}{2}$ months under appropriate visual sti:nulation.

\section{Discussion}

The results indicate that the visual system is capable of more refined control of the prehensile system at an early age than is the tactual system. Prehensile adjustment to size, shape, and hardness is more differentiated when the information is fed in visually than when it enters through the tactual mode. At the same time, from the very beginning the infant is aware of the conflict between visual and tactual that is posed by the virtual object. The response to the conflict becomes more complex with age. The 5-month-old Ss did not completely close their hands on the virtual object. This would seem to indicate that tactual feedback was beginning to control the last stages of the grasp response in such a way that its absence could stop the ongoing response. Prior to this point in development, the grasp would complete itself in the absence of tactual feedback. The incomplete grasps of the older babies are thus the first sign that the tactual modality can override vision at all. It would perhaps be more profitable to look at this phase of development as an extension of the role for touch relative to vision in the control of prehensile behavior. Vision seems to operate essentially as an anticipatory system, preparing the hand for grasping, whereas touch takes over control after the object is in the hand. This seems true of infants and adults. The information provided by the tactual system initially seems to be very poor. The poorly coordinated grasping behavior that occurs after the object is in the hand contrasts markedly with the refined anticipatory activity that occurs before that point. If the prehensile system is controlled as in Fig. 3, the change observed at 5 months could be accounted for by assuming that the tactual system simply becomes more rapid in its operation, perhaps as the result of simple maturation. Certainly clinical data would suggest that the tactile input system is somewhat lethargic at birth (Peiper, 1963) and that its speed of response increases with age.

\section{REFERENCES}

BERKELEY, G. An essay towards a new theory of vision. (First published in 1709.) In C. M. Turbayne (Ed.), Works on vision: Geonge Berkeley. Indianapolis and New York: Bobbs-Merrill, 1963.

KATZ, D. The world of colour. London: K. Paul, Trench, Trubner \& Co., 1935.

MICHOTTE, A. Causalité, permanence et realité phénoménales. Louvain, Belgium: Publications Universitaires, 1962.

PEIPER, A. Cerebral function in infancy and childhood Translation of the 3rd rev. German ed. by Benedict Nagler and Hilde Nagler. New York: Consultants Bureau, 1963.

PIAGET, J., \& INHELDER, B. La psychologie de l'enfant. Paris: Presses Universitaires de France, 1966. (Also translated from the French by Helen Weaver, New York, Basic Books, 1969.)

ROCK, J. The nature of perceptual adaptation. New York: Basic Books, 1966.

NOTE

1. Address: Department of Psychology, William James Hall, Harvard University, Cambridge, Massachusetts 02138.

(Accepted for publication November 15, 1969.) 